\title{
Effect of early percutaneous coronary intervention on one- year risk of pneumonia and pneumonia-related adverse outcomes in patients with acute myocardial infarction
}

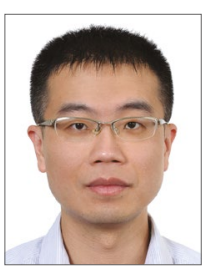

Chao-Feng Lin ${ }^{1,2,3}$, MD; Ya-Hui Chang ${ }^{4}$, MSc; Nai-Fang Chi', MD; Ming-Tsang Chuang ${ }^{6}$, MSc; Li-Nien Chien ${ }^{7 *}, \mathrm{PhD}$

1. Division of Cardiology, Department of Internal Medicine, MacKay Memorial Hospital, Taipei, Taiwan; 2. Department of Medicine, MacKay Medical College, New Taipei City, Taiwan; 3. Division of Cardiology, Department of Internal Medicine, Shuang Ho Hospital, New Taipei City, Taiwan; 4. Department of Pharmacy, MacKay Memorial Hospital, Taipei, Taiwan; 5. Department of Neurology, Shuang Ho Hospital, Taipei Medical University, New Taipei City, Taiwan; 6. School of Public Health, College of Public Health and Nutrition, Taipei Medical University, Taipei, Taiwan; 7. School of Health Care Administration, College of Management, Taipei Medical University, Taipei, Taiwan

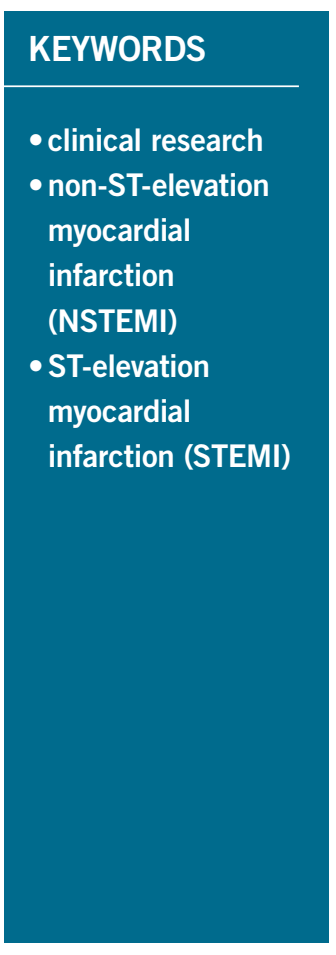

\section{Abstract}

Aims: The aim of this study was to investigate the association between early percutaneous coronary intervention (PCI) and pneumonia risk in patients with acute myocardial infarction (AMI) by using Taiwan's National Health Insurance Research Database (NHIRD).

Methods and results: In total, 4,732 patients with non-ST-elevation myocardial infarction (NSTEMI) and 5,465 with ST-elevation myocardial infarction (STEMI) who had received PCI during AMI hospitalisation (early PCI) were evaluated. Patients who did not receive PCI during AMI hospitalisation (deferred PCI) were matched through propensity score matching. The incidence rates (per 100 person-months) of pneumonia hospitalisation, pneumonia-related respiratory failure, and pneumonia-related death associated with early PCI in patients with NSTEMI were 0.36 (95\% confidence interval [CI]: 0.32-0.42), 0.12 (95\% CI: $0.10-0.16$ ), and 0.08 (95\% CI: 0.06-0.11), respectively. In patients with STEMI, the incidence rates (per 100 person-months) of the aforementioned adverse events were 0.16 (95\% CI: $0.13-0.20), 0.04$ (95\% CI: 0.03-0.06), and 0.02 (95\% CI: 0.01-0.04), respectively. After adjustment for patients' clinical variables, early PCI was associated with reduced risks of pneumonia hospitalisation (adjusted hazard ratio [aHR] 0.54, 95\% CI: 0.43-0.68, p<0.001), pneumonia-related respiratory failure (aHR 0.54, 95\% CI: 0.35-0.84, $\mathrm{p}=0.006$ ), and pneumonia-related death (aHR 0.29, 95\% CI: 0.17-0.52, $\mathrm{p}<0.001)$ in patients with NSTEMI. In patients with STEMI, early PCI was beneficial for pneumonia hospitalisation (aHR $0.62,95 \%$ CI: 0.45 $0.86, \mathrm{p}=0.004)$.

Conclusions: Early PCI might reduce the risk of pneumonia hospitalisation in patients with AMI.

\footnotetext{
*Corresponding author: School of Health Care Administration, College of Management, Taipei Medical University, No.172-1,
} Sec. 2, Keelung Rd, Da'an Dist, Taipei City 106, Taiwan.E-mail:Inchien@tmu.edu.tw 


\author{
Abbreviations \\ ACEI angiotensin-converting enzyme inhibitor \\ AMI acute myocardial infarction \\ ARB angiotensin II receptor blocker \\ CHADS $_{2}$ congestive heart failure, hypertension, age $>75$ years, \\ diabetes, previous stroke \\ CHF congestive heart failure \\ CKD chronic kidney disease \\ CLD chronic liver disease \\ COPD chronic obstructive pulmonary disease \\ CVD cerebrovascular disease \\ DM diabetes mellitus \\ HTN hypertension \\ NSAID non-steroidal anti-inflammatory drug \\ NSTEMI non-ST-elevation myocardial infarction \\ PCI percutaneous coronary intervention \\ PPI proton pump inhibitor \\ PS propensity score \\ PSM propensity score matching \\ std standard deviation \\ STEMI ST-elevation myocardial infarction
}

\section{Introduction}

Acute myocardial infarction (AMI), including ST-elevation MI (STEMI) and non-STEMI (NSTEMI), remains the leading cause of morbidity and mortality worldwide ${ }^{1}$. The risk of incident infections, including bloodstream infections, pneumonia, and urinary tract infections, is $79 \%$ higher in patients with AMI than in those without $\mathrm{AMI}^{2-4}$. In particular, pneumonia is a major infection in patients with AMI and can cause serious complications ${ }^{2-4}$. Furthermore, patients with pneumonia and AMI have a significantly higher rate of all-cause mortality than do those without $\mathrm{AMI}^{5}$. Therefore, strategies for preventing adverse cardiovascular events and incident pneumonia in patients with AMI are crucial.

Early and successful percutaneous coronary intervention (PCI) for patients with AMI yields lower rates of adverse cardiovascular events than medical treatment ${ }^{6-8}$; early PCI is particularly beneficial for patients with AMI with high cardiovascular risks ${ }^{8}$. However, the association between early PCI and reduced risks of pneumonia and pneumonia-related adverse outcomes in patients with AMI remains unclear.

This study investigated the association between early PCI and pneumonia hospitalisation as well as pneumonia-related adverse outcomes in patients with AMI. A retrospective cohort study was conducted using data from Taiwan's National Health Insurance Research Database (NHIRD).

\section{Methods}

INSTITUTIONAL REVIEW BOARD, STUDY DESIGN, AND DATA SET

This retrospective population-based cohort study was conducted using data collected from the NHIRD between 2000 and 2012. Approval for the study was received by the Joint Institutional
Review Board of Taipei Medical University (TMU-JIRB No. 201603074). The study data were provided by the National Health Insurance Administration of Taiwan, which covers $99 \%$ of the residents in Taiwan. Notably, the NHIRD contains the International Classification of Diseases, Ninth Revision, Clinical Modification (ICD-9-CM) disease diagnosis codes; treatment procedures; claims for prescribed drugs; service dates; reimbursement amounts; the demographic information of beneficiaries; and encrypted beneficiary and provider identifiers.

\section{STUDY POPULATION}

The cohort comprised patients first hospitalised for a primary diagnosis of AMI (ICD-9-CM 410) between 2001 and 2011. The date of AMI hospitalisation was considered the index date. Among all patients, we excluded those aged $<20$ years, those who were not residents in Taiwan, those with a history of pneumonia (ICD-9-CM 480-486) before the index date and concomitant pneumonia during AMI hospitalisation, and those who received a diagnosis of a malignant tumour or cancer during the study period. Furthermore, we excluded patients at a high risk for pneumonia, including those who had received mechanical ventilation therapy during AMI hospitalisation ${ }^{9}$ and coronary artery bypass grafting $^{10}$, ventricular assist device support $^{11,12}$, extracorporeal membrane oxygenation ${ }^{13}$, splenectomy, or heart transplantation ${ }^{14,15}$ within one year of follow-up. Figure 1 presents the patient selection process. Notably, patients who had and had not received PCI at their initial AMI hospitalisation comprised the early and deferred PCI groups, respectively.

\section{PROPENSITY SCORE MATCHING}

To account for potential selection bias, propensity score matching (PSM) was used to select patients with AMI with early and deferred PCI who had similar baseline characteristics but a different PCI status ${ }^{16-19}$. The covariates used to calculate the score, namely age, sex, the index year, previous or present comorbidities, and drug prescriptions, are listed in Table 1.

Previous or present comorbidities, namely cerebrovascular disease, diabetes mellitus (DM), hypertension (HTN), dyslipidaemia, chronic kidney disease, congestive heart failure (CHF), chronic obstructive pulmonary disease, asthma, chronic liver disease, dementia, Parkinson's disease, and rheumatism, were recorded if the patients had $\geq 2$ diagnostic claims in the year preceding the index date. Moreover, we calculated the $\mathrm{CHADS}_{2}$ score, which is the sum of the risk factors for CHF, HTN, DM, and stroke as well as age $>75$ years at MI diagnosis, and used it for patient matching $^{20-22}$. The history of influenza and pneumonia vaccinations and prescribed medications, namely angiotensin-converting enzyme inhibitors, angiotensin II receptor blockers, beta-blockers, antiplatelets (including thienopyridines), nitrates, statins, proton pump inhibitors, nonsteroidal anti-inflammatory drugs, and steroids, were also considered. However, prescribed medications were only considered for matching if they were used for more than three months in the year preceding the index date. 


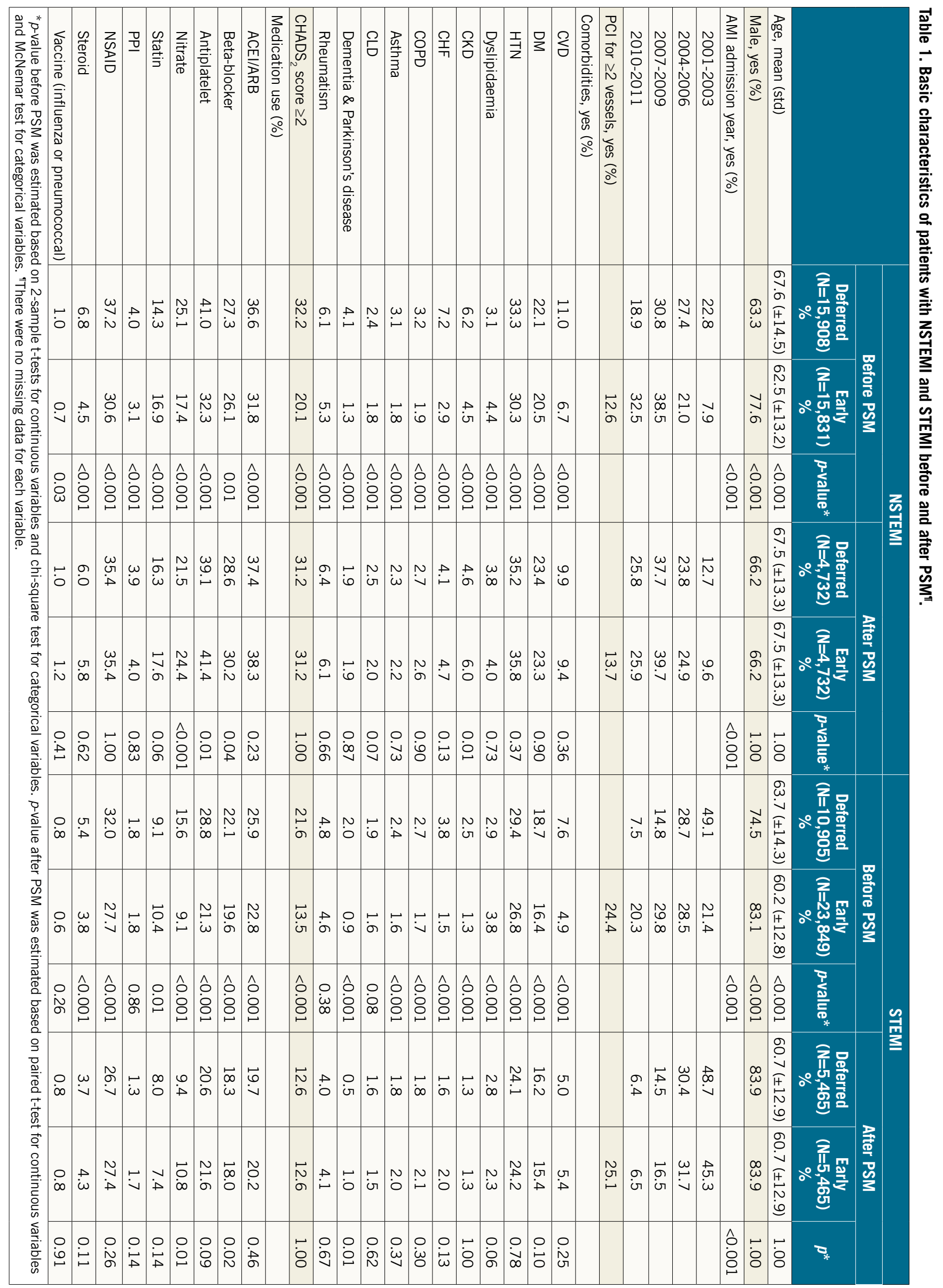




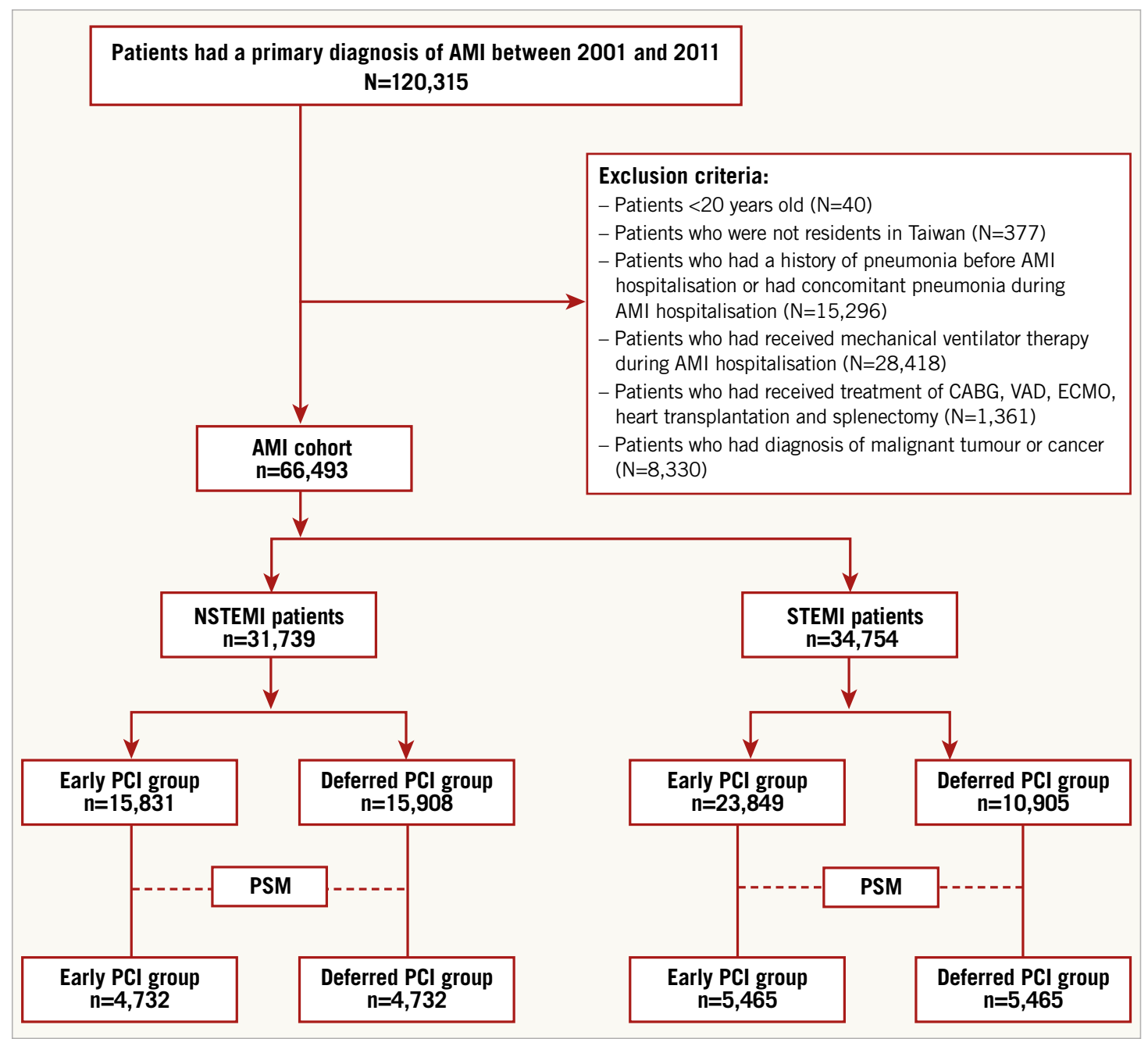

Figure 1. Flow chart of the patient selection process. AMI: acute myocardial infarction; CABG: coronary artery bypass grafting; ECMO: extracorporeal membrane oxygenation; NSTEMI: non-ST-elevation myocardial infarction; PCI: percutaneous coronary intervention; PSM: propensity score matching; STEMI: ST-elevation myocardial infarction; VAD: ventricular assist device

\section{MAIN OUTCOME MEASURES}

The main outcomes were pneumonia hospitalisation (ICD-9-CM 480-486), pneumonia-related respiratory failure requiring mechanical ventilation therapy, and pneumonia-related death. Death-related data were obtained from Taiwan's National Death Registry.

\section{STATISTICAL ANALYSIS}

A primary analysis was performed to determine the association between early PCI and the risk of main outcomes in the patients with STEMI and NSTEMI after PSM. We also performed a subgroup analysis of the patients with high cardiovascular risks (age $\geq 75$ years and $\mathrm{CHADS}_{2}$ score $\geq 2$ ). Stratified Cox proportional hazard regression was used to compare the risk of main outcomes between the early and deferred PCI groups after adjustment for the clinical variables noted in Table 1. All analyses were performed using SAS/STAT 9.2 (SAS Institute Inc., Cary, NC, USA) and Stata 12 (StataCorp LLC, College Station, TX, USA). Statistical significance was set at $\mathrm{p}<0.05$.

\section{Results}

\section{BASELINE CHARACTERISTICS}

Among all of the patients with AMI, 52.3\% had STEMI and 59.7\% had received early PCI during AMI hospitalisation. The patients with STEMI were typically younger and had fewer comorbidities, lower $\mathrm{CHADS}_{2}$ scores, and a lower rate of medication use than did those with NSTEMI (Table 1).

Before PSM, the rate of receiving early PCI was higher in the patients with STEMI than in those with NSTEMI $(68.6 \%$ vs. $49.9 \%$ ). In both the STEMI and NSTEMI cohorts, the patients who had received early PCI were younger and had fewer comorbidities and a lower $\mathrm{CHADS}_{2}$ score than those who had received deferred PCI.

After PSM, 4,732 and 5,465 patient pairs were identified from the patients with NSTEMI and STEMI, respectively. The baseline characteristics were very similar in the early and deferred PCI groups (Table 1). 
KAPLAN-MEIER ANALYSIS AND INCIDENCE RATES OF MAIN OUTCOMES IN THE NSTEMI AND STEMI COHORTS

In the NSTEMI cohort, the cumulative incidence rates of pneumonia hospitalisation and pneumonia-related death were lower in the early PCI group than in the deferred PCI group; similar results were found in the STEMI cohort (Figure 2). In the NSTEMI cohort, the incidence rates (per 100 person-months) of pneumonia hospitalisation, pneumonia-related respiratory failure, and pneumonia-related death were higher in the deferred PCI group $(0.57,95 \%$ confidence interval [CI]: $0.51-0.64 ; 0.17,95 \% \mathrm{CI}: 0.13-0.21$; and $0.17,95 \%$ CI: $0.13-0.20$, respectively) than in the early PCI group $(0.36,95 \%$ CI: $0.32-0.42$; $0.12,95 \% \mathrm{CI}: 0.10-0.16$; and $0.08,95 \% \mathrm{CI}: 0.06-$ 0.11 , respectively). In the STEMI cohort, the incidence rates (per 100 person-months) of pneumonia hospitalisation were significantly higher in the deferred PCI group $(0.22,95 \%$ CI: 0.19-0.26) than in the early PCI group $(0.16,95 \%$ CI: $0.13-0.20)$ (Figure 3).
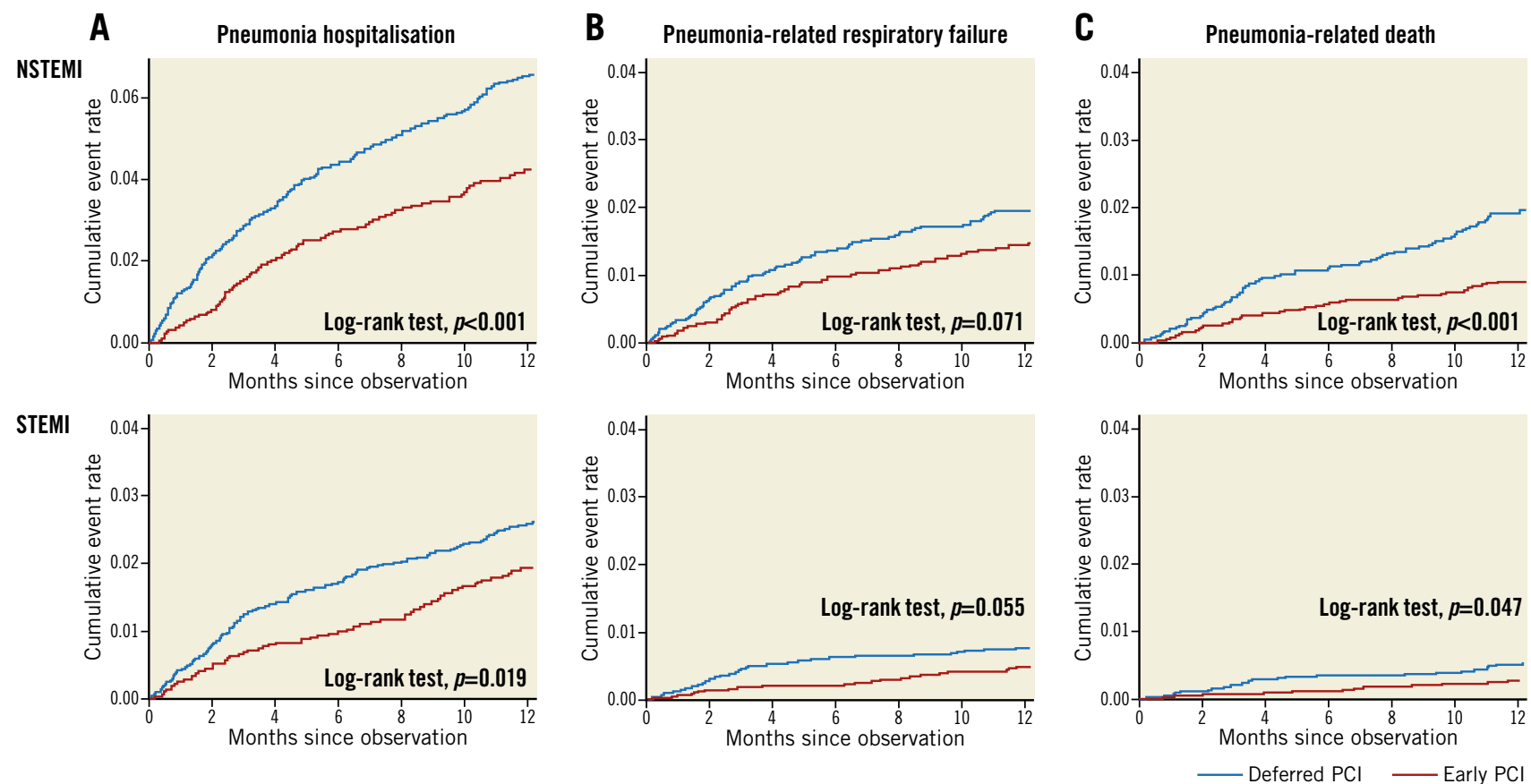

Figure 2. Kaplan-Meier curves and log-rank tests for pneumonia hospitalisation (A), pneumonia-related respiratory failure (B), and pneumonia-related death $(C)$ in patients with NSTEMI and STEMI who had received deferred PCI versus early PCI after PSM.

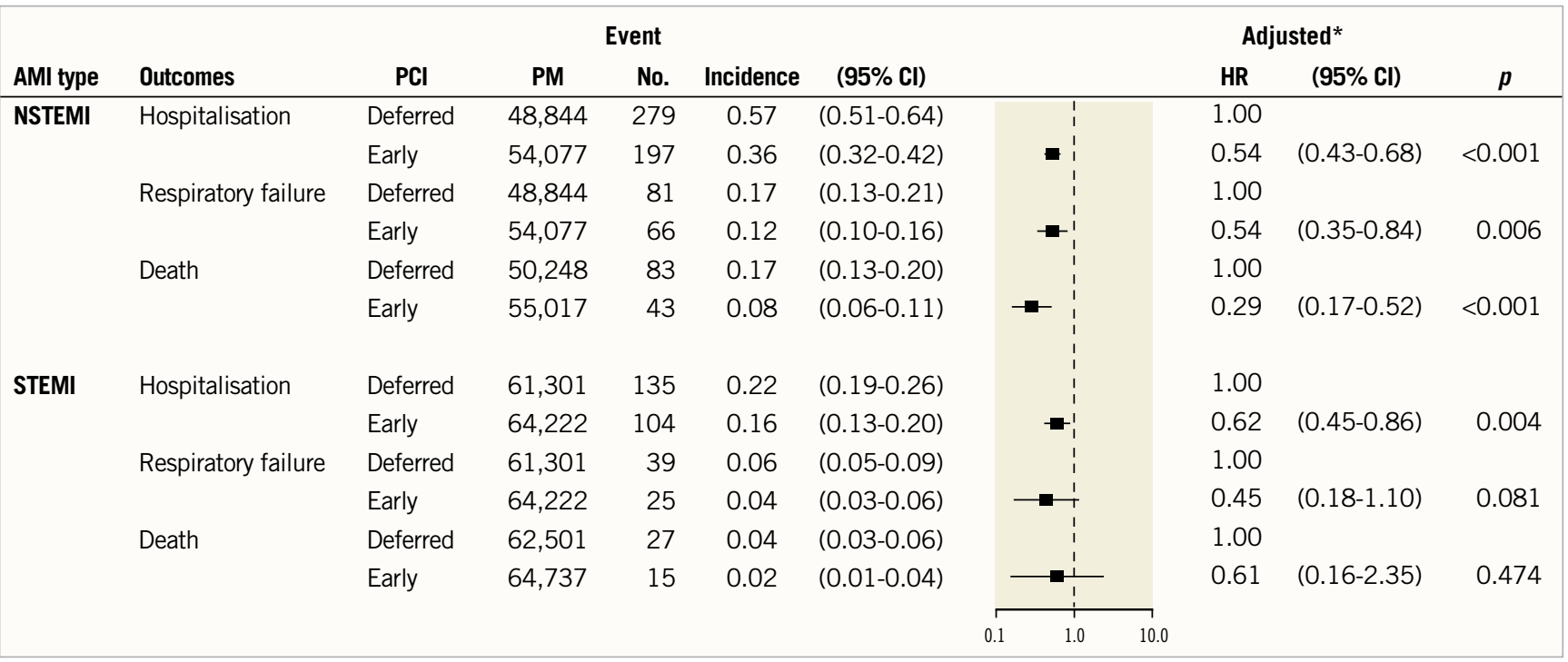

Figure 3. Incidence rates (per 100 person-months) and aHRs for pneumonia hospitalisation, pneumonia-related respiratory failure, and pneumonia-related death for patients with NSTEMI and STEMI who had received deferred PCI versus early PCI after PSM. *Results after adjustment for age, sex, the index date, previous or present comorbidities, and drug prescriptions are listed in Table 1. 


\section{EARLY PCI AND RISK OF MAIN OUTCOMES IN THE NSTEMI AND STEMI COHORTS}

After adjustment for potential risk factors, we observed that, compared with deferred PCI, early PCI in the NSTEMI cohort was associated with reduced risks of pneumonia hospitalisation (adjusted hazard ratio [aHR] 0.54, 95\% CI: 0.43-0.68, $\mathrm{p}<0.001$ ), pneumonia-related respiratory failure (aHR $0.54,95 \% \mathrm{CI}: 0.35-$ $0.84, \mathrm{p}=0.006$ ), and pneumonia-related death (aHR 0.29, 95\% CI: 0.17-0.52, $\mathrm{p}<0.001)$. However, compared with deferred PCI, early PCI in the STEMI cohort was only associated with a reduced risk of pneumonia hospitalisation (aHR 0.62, 95\% CI: 0.45-0.86, $\mathrm{p}=0.004$ ) (Figure 3).

\section{SUBGROUP ANALYSIS}

Among the patients with a $\mathrm{CHADS}_{2}$ score of $\geq 2$, the incidence rates of pneumonia hospitalisation (aHR 0.44 , 95\% CI: 0.30 $0.63, \mathrm{p}<0.001$ ), pneumonia-related respiratory failure (aHR 0.35 , 95\% CI: 0.12-0.96, $\mathrm{p}=0.041$ ), and pneumonia-related death (aHR $0.15,95 \%$ CI: $0.05-0.45, p=0.001)$ were lower in the early PCI group than in the deferred PCI group in the NSTEMI cohort. In the STEMI cohort, early PCI was associated with a lower risk of pneumonia-related death than was deferred PCI, with an aHR of 0.31 (95\% CI: 0.11-0.86, $\mathrm{p}=0.025)$. Similar results were obtained when the analysis was limited to the patients aged $\geq 75$ years (Figure 4).

\section{Discussion}

Our nationwide database comprised not only medical centres but also non-PCI-capable hospitals in Taiwan. Thus, our findings probably represent real-world data and indicate that many patients with AMI did not receive early PCI. Potential reasons for the delay between AMI and PCI include the lack of adherence to American College of Cardiology Foundation/American Heart Association guidelines, lack of implementation of quality improvement programmes, and suboptimal awareness of invasive cardiac procedures ${ }^{6,23}$.

Previous studies, as well as the present study, have reported the underutilisation of early PCI among patients with NSTEMI and high cardiovascular risks ${ }^{24-27}$. This may occur because the risk profiles of patients are perceived to increase the risks and

\begin{tabular}{|c|c|c|c|c|c|c|c|c|c|c|c|}
\hline \multirow[b]{2}{*}{ AMI type } & \multirow[b]{2}{*}{ Subgroup } & \multirow[b]{2}{*}{ Outcomes } & \multicolumn{5}{|c|}{ Event } & \multicolumn{4}{|c|}{ Adjusted* } \\
\hline & & & PCI & PM & No. & Incidence & (95\% Cl) & & HR & (95\% Cl) & $p$ \\
\hline \multirow[t]{12}{*}{ NSTEMI } & $\mathrm{CHADS}_{2} \geq 2$ & Hospitalisation & Deferred & 13,731 & 146 & 1.06 & $(0.90-1.25)$ & & 1.00 & & \\
\hline & & & Early & 16,134 & 102 & 0.63 & $(0.52-0.77)$ & - & 0.44 & $(0.30-0.63)$ & $<0.001$ \\
\hline & & Respiratory failure & Deferred & 13,731 & 47 & 0.34 & $(0.26-0.46)$ & & 1.00 & & \\
\hline & & & Early & 16,134 & 31 & 0.19 & $(0.14-0.27)$ & 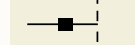 & 0.35 & $(0.12-0.96)$ & 0.041 \\
\hline & & Death & Deferred & 14,408 & 48 & 0.33 & $(0.25-0.44)$ & & 1.00 & & \\
\hline & & & Early & 16,620 & 23 & 0.14 & $(0.09-0.21)$ & $=$ & 0.15 & $(0.05-0.45)$ & 0.001 \\
\hline & Age $\geq 75$ & Hospitalisation & Deferred & 15,400 & 167 & 1.08 & $(0.93-1.26)$ & & 1.00 & & \\
\hline & & & Early & 18,619 & 125 & 0.67 & $(0.56-0.80)$ & -1 & 0.51 & $(0.37-0.70)$ & $<0.001$ \\
\hline & & Respiratory failure & Deferred & 15,400 & 57 & 0.37 & $(0.29-0.48)$ & & 1.00 & & \\
\hline & & & Early & 18,619 & 45 & 0.24 & $(0.18-0.32)$ & $\rightarrow$ & 0.45 & $(0.24-0.86)$ & 0.016 \\
\hline & & Death & Deferred & 16,120 & 66 & 0.41 & $(0.32-0.52)$ & & 1.00 & & \\
\hline & & & Early & 19,177 & 33 & 0.17 & $(0.12-0.24)$ & - & 0.17 & $(0.07-0.40)$ & $<0.001$ \\
\hline \multirow[t]{13}{*}{ STEMI } & $\mathrm{CHADS}_{2} \geq 2$ & Hospitalisation & Deferred & 6,719 & 52 & 0.77 & $(0.59-1.02)$ & & 1.00 & & \\
\hline & & & Early & 7,702 & 41 & 0.53 & $(0.39-0.72)$ & - & 0.47 & $(0.22-1.01)$ & 0.054 \\
\hline & & Respiratory failure & Deferred & 6,719 & 17 & 0.25 & $(0.16-0.41)$ & & 1.00 & & \\
\hline & & & Early & 7,702 & 12 & 0.16 & $(0.09-0.27)$ & $=$ & 0.52 & (0.08-3.34) & 0.488 \\
\hline & & Death & Deferred & 6,968 & 14 & 0.20 & $(0.12-0.34)$ & I & 1.00 & & \\
\hline & & & Early & 7,898 & 6 & 0.08 & $(0.03-0.17)$ & $\rightarrow$ & 0.31 & $(0.11-0.86)$ & 0.025 \\
\hline & Age $\geq 75$ & Hospitalisation & Deferred & 8,926 & 68 & 0.76 & $(0.60-0.97)$ & & 1.00 & & \\
\hline & & & Early & 10,181 & 54 & 0.53 & $(0.41-0.69)$ & +1 & 0.52 & $(0.30-0.91)$ & 0.022 \\
\hline & & Respiratory failure & Deferred & 8,926 & 21 & 0.24 & $(0.15-0.36)$ & & 1.00 & & \\
\hline & & & Early & 10,181 & 15 & 0.15 & $(0.09-0.24)$ & $=\frac{1}{1}$ & 0.50 & $(0.09-2.73)$ & 0.423 \\
\hline & & Death & Deferred & 9,300 & 15 & 0.16 & $(0.10-0.27)$ & 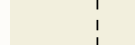 & 1.00 & & \\
\hline & & & Early & 10,429 & 11 & 0.11 & $(0.06-0.19)$ & $\rightarrow+$ & 0.57 & $(0.25-1.28)$ & 0.173 \\
\hline & & & & & & & & 1.0 & 0.0 & & \\
\hline
\end{tabular}

Figure 4. Subgroup analysis of incidence rates (per 100 person-months) and aHRs for pneumonia hospitalisation, pneumonia-related respiratory failure, and pneumonia-related death for patients with NSTEMI and STEMI who had received deferred PCI versus early PCI after PSM. *Results after adjustment for age, sex, the index date, previous or present comorbidities, and drug prescriptions are listed in Table 1. 
complications associated with invasive procedures ${ }^{26-29}$. Moreover, patients with advanced age and comorbidities who develop AMI are more likely to present with atypical symptoms rather than typical chest pain ${ }^{6,7}$. Therefore, early PCI following the successful diagnosis of AMI in such patients is typically postponed ${ }^{6,7}$. Another possible reason is that STEMI is often recognised as a more concerning AMI type because it is associated with higher in-hospital mortality rates than NSTEMI, thus leading to substantial efforts to provide early PCI at presentation ${ }^{8,27}$.

Pneumonia places a considerable burden on healthcare resources and society, mainly because of hospitalisation and lost working days ${ }^{30,31}$. Studies have identified several risk factors for pneumonia and pneumonia-related adverse events, including advanced age, $\mathrm{CHF}$, diabetes, and asthma ${ }^{30,31}$. These factors are particularly crucial for patients with NSTEMI because they typically develop the aforementioned comorbidities, as was also observed in the present study. Early PCI can be performed to reduce the risk of adverse cardiovascular events; it might also reduce the risks of pneumonia and pneumonia-related outcomes in patients with AMI, as noted herein.

Several mechanisms might explain our findings. CHF and physical limitations after AMI have been proposed to result in impaired inspiratory function; diaphragm neuromuscular alterations; intrinsic myocyte abnormalities ${ }^{32,33}$; and subsequent adverse events, including limited alveolar ventilation, impaired airway clearance, and sympathetic activation, which increase the risk of pneumonia, cardiac arrhythmias, and haemodynamic instabilities ${ }^{32}$. However, early PCI can reduce the risk of post-MI HF and improve the ability to engage in physical activities after $\mathrm{AMI}^{34,35}$, and it might have contributed to the benefits observed in the present study.

Patients with acute coronary syndrome(s) (ACS) with a $\mathrm{CHADS}_{2}$ score of $\geq 2$ had significantly increased rates of 30 -day and 10 -year mortality ${ }^{21}$. In addition, the rates of hospital mortality attributable to an ACS were considerably higher in elderly patients than in younger patients ${ }^{36}$. Studies have suggested the following strategies to improve the utilisation of PCI in patients with AMI with high cardiovascular risks and to avoid the delay in PCI: 1) educating and improving the patient's awareness of symptoms to shorten the delay between symptom onset and first medical contact, 2) establishing rapid assessment protocols to identify high-risk patients, 3 ) improving the patient's understanding and acceptance of invasive coronary intervention, 4) enhancing the physician's adherence to guidelines, and 5) increasing the availability of catheterisation laboratories and PCI-capable hospitals ${ }^{6,7,23}$.

\section{Study limitations}

First, the NHIRD does not have certain patient information, such as that on tobacco use and ambulatory status, which might be associated with the incidence of pneumonia. Second, the NHIRD does not contain some clinical information, such as the angiographic findings of PCI, extent of a patient's coronary artery disease, and severity and pathogen of pneumonia. Consequently, we could not identify the most common pathogen in patients with pneumonia. Third, the PS only considered the observed variables; therefore, hidden bias was possible. Moreover, PSM must have reduced the external validity of our study because only a subset of the treated patients was analysed. However, despite its limitations, PSM was an acceptable approach because the findings of observational studies with PSM are moderately consistent with those of randomised clinical trials ${ }^{19,37,38}$. Fourth, we could not further define the patients with primary PCI based on the population-based health insurance claims. Finally, this study was conducted using a cohort of Taiwanese patients and therefore the results might not be generalisable to other populations. Future prospective, randomised studies on the effects of early PCI are warranted to confirm our findings.

\section{Conclusions}

In this population-based PSM cohort study, the patients with NSTEMI and STEMI with early PCI had a lower risk of pneumonia requiring hospitalisation than did those with deferred PCI; these results are consistent with those for high-risk patients. Our findings suggest that early PCI significantly prevents pneumonia requiring hospitalisation.

\section{Impact on daily practice}

Early PCI may reduce the risk of pneumonia requiring hospitalisation not only in patients with NSTEMI, but also in those with STEMI.

\section{Acknowledgements}

This study was supported by the Health and Clinical Data Research Center of Taipei Medical University.

\section{Conflict of interest statement}

The authors have no conflicts of interest to declare.

\section{References}

1. Ankam J, Feldman DI, Blaha MJ, Martin SS. Improving lipid control following myocardial Infarction. Curr Opin Cardiol. 2014;29:454-66.

2. Wang HE, Shapiro NI, Griffin R, Safford MM, Judd S, Howard G. Chronic medical conditions and risk of sepsis. PLoS One. 2012;7:e48307.

3. Truffa AA, Granger CB, White KR, Newby LK, Mehta RH, Hochman JS, Patel MR, Pieper KS, Al-Khalidi HR, Armstrong PW, Lopes RD. Serious infection after acute myocardial infarction: incidence, clinical features, and outcomes. JACC Cardiovasc Interv. 2012;5:769-76.

4. Grandini LC Jr, Caramelli B. Infection complication portends poor prognosis in acute myocardial infarction. Arq Bras Cardiol. 2006;87:267-74.

5. Mortensen EM, Coley CM, Singer DE, Marrie TJ, Obrosky DS, Kapoor WN, Fine MJ. Causes of death for patients with community-acquired pneumonia: results from the Pneumonia 
Patient Outcomes Research Team cohort study. Arch Intern Med. 2002;162:1059-64.

6. American College of Emergency Physicians; Society for Cardiovascular Angiography and Interventions, O'Gara PT, Kushner FG, Ascheim DD, Casey DE Jr, Chung MK, de Lemos JA, Ettinger SM, Fang JC, Fesmire FM, Franklin BA, Granger CB, Krumholz HM, Linderbaum JA, Morrow DA, Newby LK, Ornato JP, Ou N, Radford MJ, Tamis-Holland JE, Tommaso CL, Tracy CM, Woo YJ, Zhao DX, Anderson JL, Jacobs AK, Halperin JL, Albert NM, Brindis RG, Creager MA, DeMets D, Guyton RA, Hochman JS, Kovacs RJ, Kushner FG, Ohman EM, Stevenson WG, Yancy CW. 2013 ACCF/AHA guideline for the management of ST-elevation myocardial Infarction: a report of the American College of Cardiology Foundation/American Heart Association Task Force on Practice Guidelines. J Am Coll Cardiol. 2013;61:e78-140.

7. Anderson JL, Adams CD, Antman EM, Bridges CR, Califf RM, Casey DE Jr, Chavey WE 2nd, Fesmire FM, Hochman JS, Levin TN, Lincoff AM, Peterson ED, Theroux P, Wenger NK, Wright RS, Jneid H, Ettinger SM, Ganiats TG, Philippides GJ, Jacobs AK, Halperin JL, Albert NM, Creager MA, DeMets D, Guyton RA, Kushner FG, Ohman EM, Stevenson W, Yancy CW. 2012 ACCF/AHA focused update incorporated into the ACCF/ AHA 2007 guidelines for the management of patients with unstable angina/non-ST-elevation myocardial infarction: a report of the American College of Cardiology Foundation/American Heart Association Task Force on Practice Guidelines. J Am Coll Cardiol. 2013;61:e179-347.

8. Mehta SR, Granger CB, Boden WE, Steg PG, Bassand JP, Faxon DP, Afzal R, Chrolavicius S, Jolly SS, Widimsky P, Avezum A, Rupprecht HJ, Zhu J, Col J, Natarajan MK, Horsman C, Fox KA, Yusuf S; TIMACS Investigators. Early versus delayed invasive intervention in acute coronary syndromes. $N$ Engl J Med. 2009;360:2165-75.

9. Bouadma L, Sonneville R, Garrouste-Orgeas M, Darmon M, Souweine B, Voiriot G, Kallel H, Schwebel C, GoldgranToledano D, Dumenil AS, Argaud L, Ruckly S, Jamali S, Planquette B, Adrie C, Lucet JC, Azoulay E, Timsit JF; OUTCOMEREA Study Group. Ventilator-Associated Events: Prevalence, Outcome, and Relationship With Ventilator-Associated Pneumonia. Crit Care Med. 2015;43:1798-806.

10. Likosky DS, Wallace AS, Prager RL, Jacobs JP, Zhang M, Harrington SD, Saha-Chaudhuri P, Theurer PF, Fishstrom A, Dokholyan RS, Shahian DM, Rankin JS; Michigan Society of Thoracic and Cardiovascular Surgeons Quality Collaborative. Sources of Variation in Hospital-Level Infection Rates After Coronary Artery Bypass Grafting: An Analysis of The Society of Thoracic Surgeons Adult Heart Surgery Database. Ann Thorac Surg. 2015;100:1570-5; discussion 1575-6.

11. Horvath KA, Acker MA, Chang H, Bagiella E, Smith PK, Iribarne A, Kron IL, Lackner P, Argenziano M, Ascheim DD, Gelijns AC, Michler RE, Van Patten D, Puskas JD, O’Sullivan K, Kliniewski D, Jeffries NO, O'Gara PT, Moskowitz AJ,
Blackstone EH. Blood transfusion and infection after cardiac surgery. Ann Thorac Surg. 2013;95:2194-201.

12. Tsiouris A, Paone G, Nemeh HW, Borgi J, Williams CT, Lanfear DE, Morgan JA. Short and long term outcomes of 200 patients supported by continuous-flow left ventricular assist devices. World J Cardiol. 2015;7:792-800.

13. Demondion P, Fournel L, Golmard JL, Niculescu M, Pavie A, Leprince P. Predictors of 30-day mortality and outcome in cases of myocardial infarction with cardiogenic shock treated by extracorporeal life support. Eur J Cardiothorac Surg. 2014;45:47-54.

14. Rajagopal K, Lima B, Petersen RP, Mesis RG, Daneshmand MA, Lemaire A, Felker GM, Hernandez AF, Rogers JG, Lodge AJ, Milano CA. Infectious complications in extended criteria heart transplantation. J Heart Lung Transplant. 2008;27:1217-21.

15. Camkiran Firat A, Komurcu O, Zeyneloglu P, Turker M, Sezgin A, Pirat A. Early postoperative pulmonary complications after heart transplantation. Transplant Proc. 2015;47:1214-6.

16. Austin PC. An Introduction to Propensity Score Methods for Reducing the Effects of Confounding in Observational Studies. Multivariate Behav Res. 2011;46:399-424.

17. Dehejia RH, Wahba S. Propensity Score-Matching Methods for Nonexperimental Causal Studies. The Review of Economics and Statistics. 2002;84:151-61.

18. D'Agostino RB Jr. Propensity scores in cardiovascular research. Circulation. 2007;115:2340-3.

19. Austin PC. The performance of different propensity score methods for estimating marginal hazard ratios. Stat Med. 2013;32: 2837-49.

20. Gage BF, Waterman AD, Shannon W, Boechler M, Rich MW, Radford MJ. Validation of clinical classification schemes for predicting stroke: results from the National Registry of Atrial Fibrillation. JAMA. 2001;285:2864-70.

21. Poçi D, Hartford M, Karlsson T, Herlitz J, Edvardsson N, Caidahl K. Role of the CHADS2 score in acute coronary syndromes: risk of subsequent death or stroke in patients with and without atrial fibrillation. Chest. 2012;141:1431-40.

22. Huang SS, Chen YH, Chan WL, Huang PH, Chen JW, Lin SJ. Usefulness of the CHADS2 score for prognostic stratification of patients with acute myocardial infarction. Am J Cardiol. 2014;114: 1309-14.

23. Asia-Pacific ACS Medical Management Working Group, Huo Y, Thompson P, Buddhari W, Ge J, Harding S, Ramanathan L, Reyes E, Santoso A, Tam LW, Vijayaraghavan G, Yeh HI. Challenges and solutions in medically managed ACS in the Asia-Pacific region: expert recommendations from the Asia-Pacific ACS Medical Management Working Group. Int J Cardiol. 2015;183:63-75.

24. Wallentin L, Becker RC, BudajA, Cannon CP, Emanuelsson H, Held C, Horrow J, Husted S, James S, Katus H, Mahaffey KW, Scirica BM, Skene A, Steg PG, Storey RF, Harrington RA; PLATO Investigators, Freij A, Thorsén M. Ticagrelor versus clopidogrel in patients with acute coronary syndromes. $N$ Engl J Med. 2009;361: 1045-57. 
25. Lindholm D, Varenhorst C, Cannon CP, Harrington RA, Himmelmann A, Maya J, Husted S, Steg PG, Cornel JH, Storey RF, Stevens SR, Wallentin L, James SK. Ticagrelor vs. clopidogrel in patients with non-ST-elevation acute coronary syndrome with or without revascularization: results from the PLATO trial. Eur Heart J. 2014;35:2083-93.

26. Di Bari M, Balzi D, Fracchia S, Barchielli A, Orso F, Sori A, Spini S, Carrabba N, Santoro GM, Gensini GF, Marchionni N; Acute Myocardial Infarction in Florence 2 (AMI Florence-2) Working Group. Decreased usage and increased effectiveness of percutaneous coronary intervention in complex older patients with acute coronary syndromes. Heart. 2014;100:1537-42.

27. Polonski L, Gasior M, Gierlotka M, Osadnik T, Kalarus Z, Trusz-Gluza M, Zembala M, Wilczek K, Lekston A, Zdrojewski T, Tendera M; PL-ACS Registry Pilot Group. A comparison of ST elevation versus non-ST elevation myocardial infarction outcomes in a large registry database: are non-ST myocardial infarctions associated with worse long-term prognoses? Int J Cardiol. 2011; 152:70-7.

28. Erne P, Radovanovic D, Seifert B, Bertel O, Urban P; AMIS Plus Investigators. Outcome of patients admitted with acute coronary syndrome on palliative treatment: insights from the nationwide AMIS Plus Registry 1997-2014. BMJ Open. 2015;5:e06218.

29. Hall M, Laut K, Dondo TB, Alabas OA, Brogan RA, Gutacker N, Cookson R, Norman P, Timmis A, de Belder M, Ludman PF, Gale CP; National Institute for Cardiovascular Outcomes Research (NICOR). Patient and hospital determinants of primary percutaneous coronary intervention in England, 20032013. Heart. 2016 Jan 5. [Epub ahead of print].

30. Torres A, Peetermans WE, Viegi G, Blasi F. Risk factors for community-acquired pneumonia in adults in Europe: a literature review. Thorax. 2013;68:1057-65.

31. Vinogradova Y, Hippisley-Cox J, Coupland C. Identification of new risk factors for pneumonia: population-based case-control study. Br J Gen Pract. 2009;59:e329-38.
32. Kelley RC, Ferreira LF. Diaphragm abnormalities in heart failure and aging: mechanisms and integration of cardiovascular and respiratory pathophysiology. Heart Fail Rev. 2017;22: 191-207.

33. Empinado HM, Deevska GM, Nikolova-Karakashian M, Yoo JK, Christou DD, Ferreira LF. Diaphragm dysfunction in heart failure is accompanied by increase in neutral sphingomyelinase activity and ceramide content. Eur J Heart Fail. 2014;16:519-25.

34. Terkelsen CJ, Jensen LO, Tilsted HH, Trautner S, Johnsen SP, Vach W, Bøtker HE, Thuesen L, Lassen JF. Health care system delay and heart failure in patients with ST-segment elevation myocardial infarction treated with primary percutaneous coronary intervention: follow-up of population-based medical registry data. Ann Intern Med. 2011;155:361-7.

35. Koltowski L, Koltowska-Haggstrom M, Filipiak KJ, Kochman J, Golicki D, Pietrasik A, Huczek Z, Balsam P, Scibisz A, Opolski G. Quality of life in patients with ST-segment elevation myocardial infarction undergoing percutaneous coronary intervention--radial versus femoral access (from the OCEAN RACE Trial). Am J Cardiol. 2014;114:516-21.

36. Avezum A, Makdisse M, Spencer F, Gore JM, Fox KA, Montalescot G, Eagle KA, White K, Mehta RH, Knobel E, Collet JP; GRACE Investigators. Impact of age on management and outcome of acute coronary syndrome: observations from the Global Registry of Acute Coronary Events (GRACE). Am Heart J. 2005;149:67-73.

37. Austin PC. The use of propensity score methods with survival or time-to-event outcomes: reporting measures of effect similar to those used in randomized experiments. Stat Med. 2014;33: $1242-58$

38. Dahabreh IJ, Sheldrick RC, Paulus JK, Chung M, Varvarigou V, Jafri H, Rassen JA, Trikalinos TA, Kitsios GD. Do observational studies using propensity score methods agree with randomized trials? A systematic comparison of studies on acute coronary syndromes. Eur Heart J. 2012;33:1893-901. 